\title{
UMA ANÁLISE DAS RELAÇÕES ENTRE OS JOGOS E A COMPETIÇÃO NO ENSINO DE MATEMÁTICA: UMA QUESTÃO DE MEDIAÇÃO
}

\author{
AN ANALYSIS OF THE RELATIONSHIPS BETWEEN THE GAMES AND THE \\ COMPETITION IN MATH TEACHING: A MATTER OF INTERVENTION
}

\author{
MENEZES, Fabio ${ }^{1}$ \\ RENTE, Alessandra ${ }^{2}$ \\ CASSIANO, Adriana ${ }^{3}$ \\ ORNELLAS, Carolina ${ }^{4}$
}

\begin{abstract}
RESUMO
Impulsionados por saber quais aspectos emergem das relações entre o ensino-aprendizagem da matemática através do uso de jogos, incluímos em nossas análises as situações onde os jogos podem ou não virar uma competição dependendo de uma mediação docente. Usamos como instrumento para a produção de dados um jogo desenvolvido pelo primeiro autor deste trabalho no programa Scratch, que leva ideias e compreensões intuitivas sobre a soma e subtração de números inteiros positivos e negativos já nos anos iniciais do ensino fundamental, no nosso caso, no $2^{\circ}$ ano de escolaridade. Usamos uma lente analítica que dialoga teorias sobre competição, recursos e aprendizagem em coletividade. Nossos resultados apontam para uma real e cuidadosa mudança de desenvolvimento comportamental e sociológico dos estudantes quando mudamos um estilo de mediação e fazemos um jogo virar competição, sugerindo que a aprendizagem se compromete, pois, aspectos da violência foram verificados desvirtuando o foco da matemática a ser aprendida.
\end{abstract}

PalaVRAS-ChaVe: Mediação; Ensino de Matemática; Anos Iniciais; Scratch; Jogos na Matemática.

1 Universidade do Estado do Rio de Janeiro - UERJ / Faculdade de Formação de Professores - FFP. São Gonçalo, RJ, Brasil. Secretaria Municipal de Educação de Duque de Caxias - SME. Duque de Caxias, RJ, Brasil. ORCID: http://orcid.org/0000-0003-3721-8014 e-mail: professorfabioms@gmail.com

2 Secretaria Municipal de Educação do Rio de Janeiro - SME. Rio de Janeiro, RJ, Brasil. ORCID: https://orcid.org/0000-0001-5912-0814 e-mail: ale.rente@gmail.com

3 Secretaria Municipal de Educação do Rio de Janeiro - SME. Rio de Janeiro, RJ, Brasil. ORCID: https://orcid.org/0000-0003-4330-6299 e-mail: dricaugf@bol.com.br

4 Secretaria Municipal de Educação do Rio de Janeiro - SME. Rio de Janeiro, RJ, Brasil. Secretaria Municipal de Educação de Nova Iguaçu - SME. Nova Iguaçu, RJ, Brasil. ORCID: https://orcid.org/0000-0002-84657098 e-mail: carolornellas1@gmail.com 
DOI: $10.12957 / \mathrm{e}-\mathrm{mosaicos} .2021 .47990$

\begin{abstract}
Driven by understanding which aspects emerge from the relationship between teaching and learning mathematics through the use of games, we have included in our analyzes the situations where games may or may not become a competition depending on a teaching mediation. We used as a tool for data production a game developed by the first author of this work in the Scratch, program that takes ideas and intuitive understandings about the addition and subtraction of positive and negative integers already in the early years of elementary school, in our case, in the 2nd year schooling. We use an analytical lens that dialogues theories about competition, resources and collective learning. Our results point to a real and careful change in behavioral and sociological development of students when we change a mediation style and make a game of competition, suggesting that learning is compromised, since aspects of violence were verified, distorting the focus of mathematics to be learned.
\end{abstract}

KeYwords: Mediation; Mathematics teaching; Early Years; Scratch; Games in Mathematics.

\title{
INTRODUÇÃO
}

É comum no meio escolar e acadêmico, e até no senso comum, escutarmos que utilizar nas aulas de matemática algum método com teor lúdico é uma boa estratégia para angariar a atenção, 0 interesse e, consequentemente, aumentar a confiança em um processo de ensino-aprendizagem de sucesso. Tais considerações incentivaram algumas pesquisas que buscam sustentar essa hipótese. Assim, também entendemos ser necessário aprofundar o conhecimento sobre as práticas ou métodos lúdicos que serão ou estão sendo empregados, sobre suas premissas epistemológicas, estudando suas consequências nos planejamentos e nas práticas escolares.

Nós, autores, somos professores da escola de Educação Básica e sentimo-nos, dessa forma, impulsionados a investigar tais premissas e comunicar nossas reflexões neste artigo, pois o aspecto lúdico se faz presente em diversas situações cotidianas dentro e fora da sala de aula, como diversão ou brincadeiras, um jogo ou um debate de ideias, de alguma forma estão enraizados em nossa própria ideia de civilização e convivência em sociedade.

No caso específico dos jogos entendemos que estes são reveladores e consolidadores de diversos outros aspectos da vida humana, sabendo que são atividades que tomam por base as regras e a ordem, e tomamos emprestado o que nos diz Huizinga (1990, p.16, grifos da autora) deles serem:

Atividade livre, conscientemente tomada como não-séria e exterior à vida habitual, mas ao mesmo tempo capaz de absorver o jogador de maneira 
DOI: $10.12957 / \mathrm{e}-\mathrm{mosaicos} .2021 .47990$

intensa e total. É uma atividade desligada de todo e qualquer interesse material, com a qual não se pode obter qualquer lucro, praticada dentro dos limites espaciais e temporais próprios, segundo uma certa ordem e certas regras. [...]

Observando esta definição cremos serem as regras que, implicitamente, trazem a ordenação e os limites de cada jogador e do próprio jogo, tanto espaciais quanto temporais, que regulam as atividades, as ações. Neste sentido, seria desejável que a escola, em seu ensino sistematizado, aproveitando-se de teorias sobre a práxis lúdica, fizesse uso significativo das atividades lúdicas como os jogos em prol do desenvolvimento escolar, social e humano.

Mas de que maneira os professores, as escolas de modo geral, estão se apropriando dos jogos como método lúdico-pedagógico na ajuda ao processo do ensinoaprendizagem sistematizado? Nossa preocupação é quando estão favorecendo o "aprender a competir". Por causa dessa possibilidade, percebemos que deveríamos pensar ainda mais profundamente sobre tal método, ou seja, da mesma forma que nos preocupamos neste artigo em sustentar a ideia da ludicidade do jogo como uma boa estratégia no auxílio ao processo de ensino-aprendizagem, também nos preocupamos com a ocorrência e incentivo à competição quando da utilização desta estratégia, com vistas a algumas consequências sociais advindas desta ideia.

A palavra competição per se, tomada isoladamente, pode ser (re)definida dentro de cada campo de estudo, seja social ou científico. Em biologia, por exemplo, segundo indicam Townsend, Begon e Harper (2010) competição é a interação de indivíduos da mesma espécie ou espécie diferentes (humana, animal ou vegetal) que disputam alimento, território, luminosidade, emprego, pela fêmea, pelo macho, etc. Logo, nessa perspectiva, ela pode ocorrer entre a mesma espécie ou entre espécies diferentes, mas em quaisquer casos há um processo seletivo que, na maioria das vezes, resulta em extinção de "indivíduos" com baixo poder adaptativo. Definição bastante corroborada também pelo meio empresarial no mundo em que vivemos. Ou pelo menos deixa essa sensação.

São muitas as inquietações e questionamentos acerca do ensino sistematizado através de jogos, porém a questão que procuramos responder neste artigo é: "Que aspectos emergem na mobilização das relações entre ensino e aprendizagem de matemática usando jogos, quando o jogo é ou não é transformado em uma competição?". Mergulhando em alguns referenciais teóricos e em alguns relatos de experiência edificamos nossas impressões sobre as relações entre os jogos e a competição no contexto escolar do ensino-aprendizagem da matemática nos anos iniciais. 
DOI: $10.12957 /$ e-mosaicos.2021.47990

Nosso objetivo é trazer uma sucessão de reflexões sobre o uso dos jogos como atividades lúdicas em aulas de matemática, que muitas vezes geram (ou são gerados por) uma competição, desde os anos iniciais do Ensino Fundamental - no nosso caso, fizemos a observação em uma turma de $2^{\circ}$ ano do Ensino Fundamental. Para isso, aproveitamos a parceria promovida entre o Laboratório Sustentável de Matemática (LSM) ${ }^{5}$ e uma escola da rede municipal do Rio de Janeiro - lócus da prática de três autoras deste artigo - para investigarmos o que ocorre quando mediamos a aprendizagem com o uso de jogos para ser ou não uma competição, utilizando nossa própria prática ao usarmos jogos como meio de pesquisa.

\section{JOGAR SEM COMPETIR?}

Não é incomum que a primeira coisa que nos venha à mente quando entoamos a palavra jogo seja a noção de competição. Normalmente, podemos, sim, relacionar a competição a alguma espécie de jogo. Vejam, por exemplo, os jogos olímpicos, segundo Elias (1992) eles foram concebidos como uma representação mimética e 'pacífica' de uma guerra entre povos, um modo de reuni-los sem que se matassem uns aos outros, de maneira que essa matança fosse substituída por uma condição de vencedor e vencido.

Reparamos aqui que competir não é o fim do confronto, apenas a troca de uma forma reconhecidamente violenta por uma outra violência que é, podemos dizer, controlada pelas regras e pela ordem que os jogos impõem. Mas afirmar que jogar é competir é verdadeiro? Será que sempre que jogamos estamos a competir no sentido de disputar uma classificação? E mais, será que isso é sempre uma não-virtude no sentido escolar? São muitas as reflexões que guiaram nossa pesquisa.

Segundo Silva (2010) podemos enxergar o jogo como uma manifestação construída social e historicamente pelos seres humanos e, portanto, algo que faz parte da realidade social, inclusive, das crianças. Esta análise é uma das que ajudam a sustentar a proficuidade da sistematização dos jogos a fim de que eles se tornem partes intencionais do processo de ensino-aprendizagem, se tornem pedagógicos. Neste sentido, em se tratando da matemática ser considerada por muitos como algo difícil de aprender, seja pelo método ou pelo conteúdo em questão, as tendências atuais relacionadas ao ensinoaprendizagem de matemática também trazem no uso de jogos uma metodologia eficaz para esse processo.

Dessa forma, pensamos que a inserção dos jogos deve ser algo que faça sentido e seja significativo na/para a vida dos estudantes que, em primeira instância:

5 Uma rede de professores que compartilha e articula suas práticas, a produção e uso de seus materiais, virtual e presencialmente, cujo primeiro autor é um dos coordenadores virtuais: https://www.laboratoriosustentaveldematematica.com/ 


\section{NQ1 e-Mosaicos}

Revista Multidisciplinar de Ensino, Pesquisa, Extensão e Cultura do Instituto de Aplicação Fernando Rodrigues da Silveira (CAp-UERJ)

V. 10 - N. 23 - Janeiro-Abril de 2021 - ISSN 2316-9303

DOI: $10.12957 / \mathrm{e}-\mathrm{mosaicos} .2021 .47990$

[...] Ihe possibilite um prazer em aprender, não pelo utilitarismo, mas pela investigação, ação e participação coletiva de um "todo" que constitui uma sociedade crítica e atuante, leva-nos a propor a inserção do jogo no ambiente educacional, de forma a conferir a esse ensino espaços lúdicos de aprendizagem. (GRANDO, 2000, p.15)

Nossa perspectiva, claramente, pressupõe-se que nem todo jogo leva a uma competição. É possível criar ambientes lúdico-pedagógicos cooperativos ou colaborativos através de jogos que não sejam para ganhar do outro a qualquer custo, mas a ganhar com o outro. A aprender enquanto está com o outro, assim como Brotto (1999) sugere, aprender com o ganhar e perder junto com o outro e não aprender a ganhar e perder do outro.

Mesmo quando estamos num jogo para competir, são as regras que dão os limites e a ordem do que acontece e é para elas que olhamos primeiro. De quem são as regras do jogo, quem as cria? Que ordem é essa e quem a determina? Normalmente, não se tem autonomia para mudar as regras de um jogo e, talvez, esteja aí um ponto que pode ser chave para diferenciar um jogo tão somente de competição de outros que envolvem cooperação ou colaboração e que possam ser chamados de pedagógicos. Rondinelli (2019) elenca algumas características que transformam uma atividade em um jogo pedagógico, que resumidamente mostramos como um mapa conceitual (FIGURA 1) a seguir:

Figura 1 - Características de um jogo pedagógico

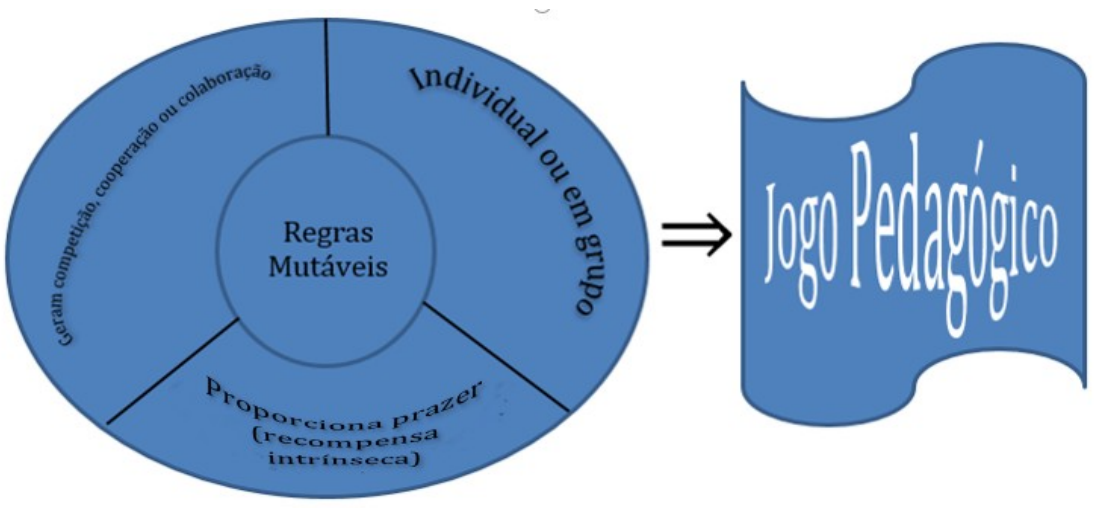

Fonte: Autores (2019)

Nossa leitura sobre as características de um jogo pedagógico descritos no mapa conceitual acima indica que cabem às regras decidirem sobre a ordem e se um jogo será apenas competitivo ou não, se haverá mais ou menos interatividade entre os jogadores, se trará mais ou menos recompensas individuais ou coletivas e cumprirá o papel de ponte para o saber e formação humana. Reparamos também, ainda que possamos tecer críticas 
DOI: $10.12957 / \mathrm{e}-\mathrm{mosaicos} .2021 .47990$

a tal documento, que na $\mathrm{BNCC}^{6}$ (2017) é possível perceber considerações onde identificamos a importância do uso de jogos no desenvolvimento de algumas das pretendidas competências gerais, por exemplo:

- A interação social dos jogos auxilia a competência geral 9:

Exercitar a empatia, o diálogo, a resolução de conflitos e a cooperação, fazendo-se respeitar e promovendo o respeito ao outro e aos direitos humanos, com acolhimento e valorização da diversidade de indivíduos e de grupos sociais, seus saberes, identidades, culturas e potencialidades, sem preconceitos de qualquer natureza. (BNCC, 2017, p.10)

- Com seu código de regras e condutas os jogos auxiliam na competência geral 10 na busca do "agir pessoal e coletivamente com autonomia, responsabilidade, flexibilidade, resiliência e determinação, tomando decisões com base em princípios éticos, democráticos, inclusivos, sustentáveis e solidários" (BNCC, 2017, p.10).

E também em algumas competências específicas como:

- Na busca por estratégias na resolução de problemas ou nas melhores jogadas ajuda a buscar cumprir a competência específica 2 de matemática que é o de "desenvolver o raciocínio lógico, o espírito de investigação e a capacidade de produzir argumentos convincentes, recorrendo aos conhecimentos matemáticos para compreender e atuar no mundo" (BNCC, 2017, p.265); e

- Auxiliando na criação de relações entre diferentes conteúdos, ou entre os conteúdos e o cotidiano, os jogos influenciam a competência específica 3 de matemática, pois:

Compreender as relações entre conceitos e procedimentos dos diferentes campos da Matemática (Aritmética, Álgebra, Geometria, Estatística e Probabilidade) e de outras áreas do conhecimento, sentindo segurança quanto à própria capacidade de construir e aplicar conhecimentos matemáticos, desenvolvendo a autoestima e a perseverança na busca de soluções. (BNCC, 2017, p.265)

Intuímos assim que, sendo os jogos parte da vida social dos seres humanos, eles têm importância enquanto estratégia escolar de ensino. Nossas investigações e estudos indicaram que é possível realizar jogos educacionais que tenham concepções diferentes daquelas de senso comum e de outros referenciais que admiram a competição per se. São jogos comumente chamados no meio educacional de colaborativos e cooperativos.

6 Base Nacional Comum Curricular brasileira 
DOI: $10.12957 / \mathrm{e}-\mathrm{mosaicos} .2021 .47990$

Decidimos, porém, diferenciar um do outro, mesmo que essas duas palavras tenham praticamente a mesma origem etimológica - trabalhar junto -, por entender que a conotação semântica dada a cada uma delas é diferente.

Para nós, enquanto jogos cooperativos ocorrem num agrupamento de indivíduos com o objetivo de aumentar o poder de reconhecimento do grupo, visando o melhor retorno pessoal, colaborar ocorre num agrupamento que considera essa participação de maneira mais ampla e sistêmica, onde se busca um interesse de benefício comum que prevalece sobre os interesses individuais. Mesmo que nos dois modelos haja trabalho em grupo, quando cooperamos, o objeto individual está em primeiro lugar para depois considerar a coletividade, na colaboração há o compartilhar de esforços primeiro para uma melhor performance do coletivo para depois se colher frutos individuais.

Sem juízo de valor sobre o somente competir ao jogar, mas claramente fazendo uma escolha sobre um tipo de premissa escolar diferente desta e mostrando algumas sustentações teóricas, nossa maneira de apresentar os jogos no contexto escolar é como uma prática pedagógica que, de acordo com as ideias de Bernstein (2003), pode ser entendida como um empreendimento social no qual há participantes encarregados de ensinar e de aprender. No caso dos jogos colaborativos e cooperativos escolares, as funções são mutuamente de todos os participantes, inclusive docente.

[...] desde os começos do processo, vá ficando mais claro que, embora diferentes entre si, quem forma se forma e re-forma ao formar e quem é formado forma-se e forma ao ser formado. É neste sentido que ensinar não é transferir conhecimentos[...] Quem ensina aprende ao ensinar e quem apende ensina ao aprender... Foi assim, socialmente aprendendo, que ao longo dos tempos mulheres e homens perceberam que era possível depois, preciso - trabalhar maneiras, caminhos, métodos de ensinar. (FREIRE, 1996 ed.2002, p.25-26)

Assim como propõe Freire (1996), o jogo como atividade socialmente construída foi sendo redescoberto também como uma maneira, caminho ou método de ensino e é possível, no nosso caso desejável, que eles não sejam apenas competitivos, mas que busquem formação social mútua.

\section{Jogos EM AULAS DE MATEMÁtICA(s)}

As premissas dos usos de jogos em aulas de matemática(s) estão alinhadas com a perspectiva de Grando (2000) de levar ao estudante a possibilidade de estabelecer um sistema de relações entre a prática vivenciada e a construção e estruturação do vivido, 
DOI: $10.12957 / \mathrm{e}-\mathrm{mosaicos} .2021 .47990$

produzindo conhecimento matemático. Como entendemos ser a matemática uma construção social situada no tempo e espaço em que ocorre, também decorrente dos recursos existentes, ousamos a dizer que o que se produz são matemáticas - na pluralidade - e saberes sobre elas.

Ainda em defesa do uso de jogos em sala de aula, Smole, Diniz e Milani (2007) destacam o importante papel deste recurso afirmando que:

[...] a interação entre os alunos, a socialização de procedimentos encontrados para solucionar questões e a troca de informações são elementos indispensáveis em uma proposta que visa uma melhor aprendizagem em matemática. Em nossa opinião, o jogo é uma das formas mais adequadas para que a socialização ocorra e permita a aprendizagem. (SMOLE; DINIZ; MILANI, 2007, p.13)

Contudo, Boaler (2018) destaca a importância das escolhas desses jogos e nas intervenções feitas, no desenvolvimento do que ela chama de mentalidades matemáticas, e revela em seu estudo com bases na neurociência que:

Outra forma de dar aos estudantes oportunidades para desenvolver um pensamento em uma abordagem conceitual para a matemática é envolvêlos em aplicativos e jogos de matemática que abordem a matéria conceitualmente. A maioria dos aplicativos e jogos de matemática é inútil, encorajando treino e memorização mecânica. (BOALER, 2018, p.46)

Nesse sentido e indo além, acreditamos que a produção de maneiras de ensinar e aprender matemática(s) sejam situadas socialmente no tempo e no espaço (WENGER, 1998) e que a escola esteja no centro da "busca por um ensino que considere o aluno como sujeito do processo, que seja significativo para o aluno, que the proporcione um ambiente favorável à imaginação, à criação, à reflexão" (GRANDO, 2000, p.15), coisa que muitas vezes se consegue com atividades lúdicas como a escolha de um jogo que busque abordagem mais centrada no conceitual e não especificamente num "fato matemático" (BOALER, 2018).

O jogo de cunho pedagógico é, dessa forma, também um recurso situado. Adler (1998a) argumenta que recursos em uso no contexto da educação matemática são tanto substantivo quanto como verbo, tanto como objeto quanto como ação. Adler (2000) enxerga sob a ótica das funções visíveis e invisíveis dos recursos o conceito de transparência de um recurso didático. Visíveis, de modo que possam ser usados, manipulados, que se possa entender quais os seus mecanismos e invisíveis, de modo que se possa ver através deles, para que se possa aprender com eles o que está por trás de 
DOI: $10.12957 /$ e-mosaicos.2021.47990

seu uso e que se pretende dar à luz. Situado em um contexto, esta conceituaçã̃o está ligada ao fato de que o recurso em si não é nada, o uso que se faz dele é que tem importância.

Nossa crença nos jogos como um útil recurso e método de ensino de matemáticas, vão além de considerar o desenvolvimento do raciocínio lógico através da tomada de decisões e escolhas, mas o de dar vazão à criatividade, à perda do medo de errar e a de confrontar e resolver situações reais que podem motivar estudantes a perceberem o valor das matemáticas como ciência que atua em suas vidas em sociedade. Contudo, Bezerra e Bandeira (2011) nos lembra que crianças e adultos pensam diferentes e para que ocorra este efeito desejado, a atuação do professor como mediador não se resume a uma colonizadora forma de ensinar estudantes a jogar, mas de fazer o acompanhamento de como jogam e instruí-los a construir suas próprias regras para que possam entender 0 objetivo por trás de cada jogo.

Para ajudar a interpretar a intencionalidade das atividades com jogos, destacamos que Miorim e Fiorentini $(1997$, p.7) enfatizam que o uso dos jogos pode acontecer "[...]no início de um novo conteúdo com a finalidade de despertar o interesse da criança ou no final com o intuito de fixar a aprendizagem e reforçar o desenvolvimento de atitudes e habilidades" e que Lara (2004) os categoriza em: jogos de construção, de treinamento, de aprofundamento e estratégicos. Onde na primeira categoria se busca alternativas para resolver problemas, na segunda se propõe à memorização, na terceira como uma busca para além de um conteúdo e na quarta uma proposta onde busca múltiplas alternativas para se resolver um problema.

Com base neste mini diálogo sobre a intencionalidade dos jogos, apresentaremos um exemplo exploratório de seus usos, tomando como hipóteses as discussões feitas aqui, através do qual faremos uma análise sobre a nossa mediação considerando a existência de cada categoria - intencionalidade - sob uma perspectiva de formação social. Dentro das análises não nos furtaremos a comentar sobre a presença de ações de mediação para a competição, cooperação ou colaboração presentes nas atividades e assim deixar nossas impressões acerca das causas e consequências de cada uma delas, destacando os seus momentos. No entanto, antes se faz necessário relatar qual tipo de jogo foi utilizado, como faremos a seguir.

\section{O JOGO SCRATCH NO DESERTO: ORIGEM E APLICAÇÃO DA ATIVIDADE}

A atividade que se transformou num jogo e ganhou o nome de Scratch no Deserto surge no contexto da colaboração entre o LSM - envolvendo um dos seus coordenadores - e uma escola da rede municipal do Rio de Janeiro, junto a duas de suas professoras. Através dos diversos encontros para estudos e planejamento coletivo entre eles, dentre os quais foi debatido não só o conteúdo, mas como ensiná-lo, decidiram-se por explorar os 
DOI: $10.12957 / \mathrm{e}-\mathrm{mosaicos} .2021 .47990$

significados das operações matemáticas e de como reforçariam a noção de dezenas, maior necessidade à época da especificidade do ano de escolaridade em que atuavam essas professoras.

Depois de construído (FIGURA 2) e até feito uso de materiais concretos existentes no mercado como o Material Dourado para o ensino do sistema de numeração decimal e suas operações, mesmo não estando dentro da etapa curricular o ensino das operações com negativos, devido à curiosidade dos estudantes e entendendo que tais números são parte do cotidiano dos mesmos, as professoras decidiram ensinar tal conceito matemático. Então elaboraram um jogo partir das orientações das professoras e do conhecimento matemático e do programa Scratch do coordenador do LSM.

\section{Figura 2 - Material 10 TROCA, produzido para ser usado com Material Dourado} em operações de soma e subtração.

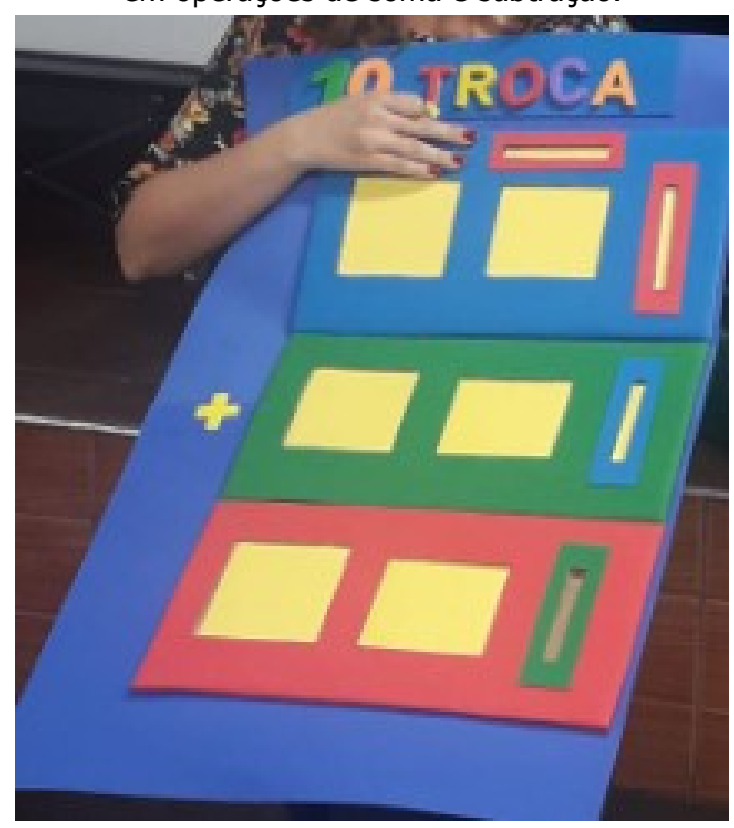

Fonte: Autores (2019)

O jogo foi desenvolvido e testado com dois alunos do $2^{\circ}$ ano de escolaridade, mas de forma individualizada, por aquelas professoras no ano de 2018. Funcionando assim: os números positivos e negativos percorrem a tela do jogo aleatoriamente e o gato - que tem o nome de Scratch - precisa tocar nos números até que a soma atinja uma dezena positiva (FIGURA 3). Porém, como não houve tempo hábil para a aplicação deste jogo em uma turma completa naquele ano, coube a nós, autores deste artigo, experimentar e explorar tal jogo em aplicação coletiva em 2019. Todavia, cabe lembrar que nosso olhar focou, para além do desenvolvimento dos estudantes em contato com esse conteúdo já no segundo ano de escolaridade, nos resultados da mediação no uso do jogo. 


\section{9:-Mosicos}

DOI: $10.12957 / \mathrm{e}-\mathrm{mosaicos} .2021 .47990$

Figura 3 - Telas inicial à esquerda e com os números positivos e negativos do jogo Scratch no Deserto à direita.

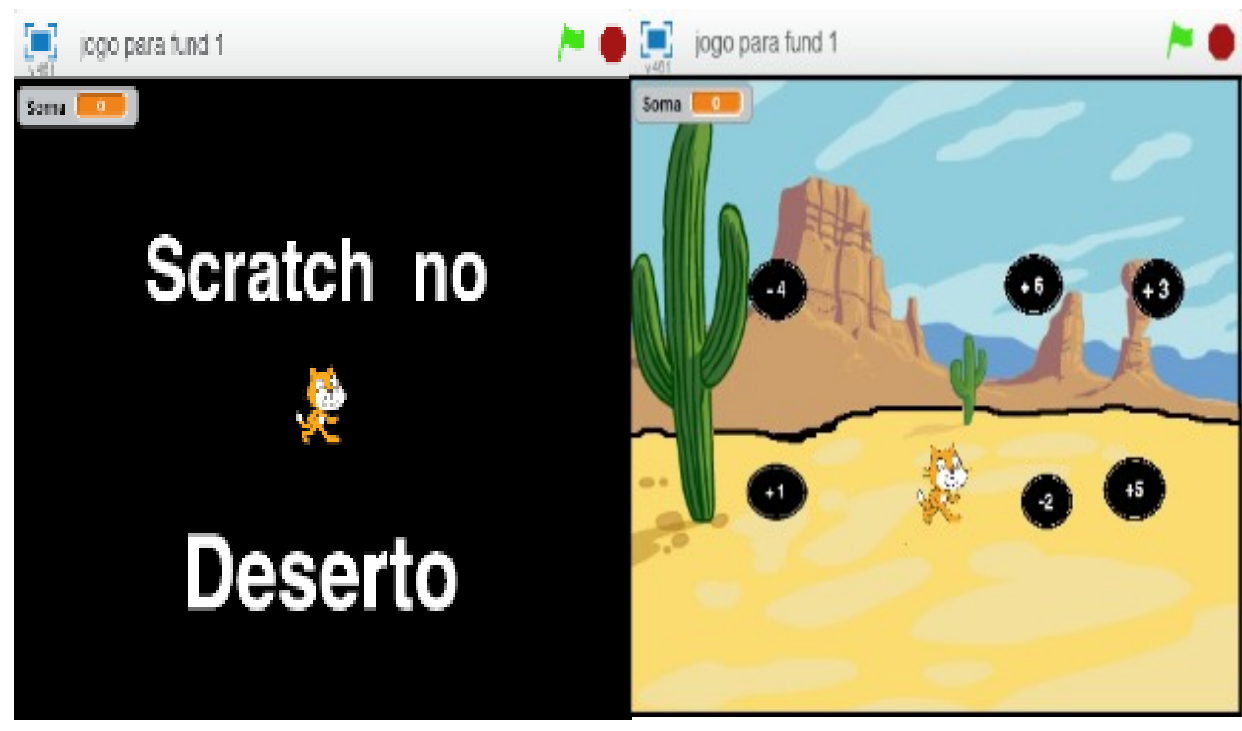

Fonte: Autores (2019)

\section{APLICAÇÃo INDIVIDUAL}

Antes da aplicação coletiva em sala de aula, aplicamos novamente individualmente de forma piloto junto a dois alunos, um do $2^{\circ}$ e outro do $3^{\circ}$ ano de escolaridade, não só para compor nossas análises situadamente mas para que pudéssemos ajustar o que fosse preciso para a aplicação coletiva em sala de aula. Nesta aplicação individual observamos que os dois alunos nos apresentaram os seguintes aspectos:

- Estranhamento: Ao chegar na sala da aplicação do jogo, ouviram as instruções, mas não sabiam o que era para fazer no jogo, pois aparentaram nervosismo por causa da novidade e por estarem fora de seu ambiente de conforto - a sala de aula;

- Aprenderam apenas o uso dos recursos do jogo: Após mediação a fim de que aprendessem como jogar e se familiarizassem com as teclas e dificuldades motoras impostas pelo computador, compreenderam os comandos que deviam ser feitos durante 0 jogo, porém ainda sem entender o objetivo, ou seja, não sabiam ainda que os faria vencer o jogo. Buscaram então pegar os números aleatoriamente;

- Aprenderam com o jogo: Fizemos nova mediação e enfatizamos as regras e o objetivo do jogo de se conseguir formar uma dezena, ainda que os mesmos já tivessem sido comunicados de forma sonora e visual pelo próprio jogo - invisíveis, aparentemente pelo deslumbramento manifestado com a novidade tanto visual quanto pedagógica. Dessa 
DOI: $10.12957 / \mathrm{e}-\mathrm{mosaicos} .2021 .47990$

forma, naturalmente descobriram o padrão de comportamento da soma que se realizava juntando negativos com positivos e negativos com negativos;

Professor-pesquisador ${ }^{7}$ 1: Está tudo bem...quer ler e ouvir as instruções?

Aluno 1: Sim. Eu fiquei meio nervoso...

Professor-pesquisador 1: Você sabe qual é a tecla espaço? Repare que precisa apertá-la para começar o jogo.

Aluno 1: É essa? - apontou para a tecla correta.

Professor-pesquisador 1: Sim. E o mouse?

Aluno 1: Isso eu sei.

$[\ldots]$

Aluno 1: Ah...entendi! Já sei o que fazer! Se tocar no negativo eu tenho que colocar mais positivos até passar do zero até chegar no dez. Minha turma vai gostar. (Diálogo entre professor e aluno, 2019).

- Rapidez de respostas: A cada vez que jogavam e se tornavam mais familiarizados tanto com o computador quanto com o jogo, focaram-se mais na atividade matemática por trás do jogo.

Notamos os mesmos aspectos e reações nos dois alunos: houve nervosismo, curiosidade, motivação ao se depararem com a proposta do jogo, mas em nenhum momento esboçaram estranhamento com a presença dos números negativos se movimentando pela tela ou quando o resultado final ficava negativo. Quando esta última situação ocorria, apenas ajustavam a soma até chegar à dezena positiva buscando tocar nos positivos e quando o resultado passava da dezena, apenas buscavam os negativos. A cada vez que jogavam se familiarizavam com o computador e com o jogo resolvendo os desafios cada vez mais rápidos, pois percebiam os padrões envolvidos e afinavam a sua parte motora. Quando as dificuldades sobre o recurso tornaram-se mais transparentes (ADLER, 2000) - os movimentos e a parte gráfica ficavam cada vez mais invisíveis/familiares - puderam focar na matemática por trás do jogo.

Para a aplicação coletiva escolhemos a turma do $2^{\circ}$ ano de escolaridade por entendermos que nosso foco seria na mediação do uso do jogo e nas inferências que poderíamos fazer, dessa forma uma turma com idade menor nos pareceu mais interessante.

7 Nos referimos assim aos autores deste artigo, pois são pesquisadores e professores da escola de Educação Básica. 
DOI: $10.12957 / \mathrm{e}-\mathrm{mosaicos} .2021 .47990$

\section{APLICAÇÃo COLETIVA}

Cabe reforçar aqui que essa pesquisa se processa numa escola que pertence à $6^{a}$ Coordenadoria Regional de Educação do município do Rio de Janeiro, situada no bairro Parque Anchieta - numa região limítrofe com o município de Nilópolis, da Baixada Fluminense - e com alunos e alunas de uma turma de $2^{\circ}$ ano que, em sua maioria, encontram-se em situação de vulnerabilidade social segundo informações da própria gestão desta escola.

Assim que propusemos a atividade com o jogo que usa o computador na turma escolhida, notamos a curiosidade não só sobre a atividade, mas em relação ao próprio computador. Ou seja, provocamos uma motivação para a aprendizagem. Apresentamos nossa proposta deixando claro que queríamos buscar aprender. Porém uma fala de aluno nos chamou a atenção e relatamos aqui:

\section{Aluno 2: Aprender a ganhar dinheiro?}

Professor-pesquisador 1: Mas tudo que se aprende é para ganhar dinheiro? Por que você perguntou isso?

Aluno 2: Não. Mas ganhar dinheiro é bom porque dá pra fazer e comprar coisas.

Professor-pesquisador 1: Então, essa não é para ganhar dinheiro, é para ter prazer e aproveitar.

Professor-pesquisador 2: Que tal pensar que nem tudo dá para ser comprado?

Aluno 2: hum...entendi!

\section{[...]}

Aluna 3: Mas tem que ensinar a todo mundo, pois ninguém sabe jogar isso. (Diálogo entre professores e um aluno, 2019).

O que buscamos inicialmente era tentar responder à pergunta sem demovê-los da ideia de que no mundo em que vivemos também se pensa em ganhar dinheiro, mas que era preciso relativizar tal valor. Com a fala de que precisaríamos ensinar a todos, voltamos a atenção para o jogo em si e percebemos logo a dificuldade com o recurso computador, pois para jogar era preciso reconhecer os nomes das teclas e isso ainda parecia ser novo aos alunos. Enquanto a tela do jogo já aparecia projetada no quadro branco da sala de aula ensinávamos os nomes das teclas do computador que importavam para o jogo. Assim perceberam que, para além das letras, as outras teclas possuíam nomes especiais: estavam reconhecendo e aprendendo o recurso.

Passada a primeira fase de reconhecimento, passamos a convidar alunos que quisessem experimentar o jogo. Para tentarmos dar equidade aos gêneros, chamamos 


\section{NQ1 e-Mosaicos}

Revista Multidisciplinar de Ensino, Pesquisa, Extensão e Cultura do Instituto de Aplicação Fernando Rodrigues da Silveira (CAp-UERJ)

V. 10 - N. 23 - Janeiro-Abril de 2021 - ISSN 2316-9303

DOI: $10.12957 / \mathrm{e}-\mathrm{mosaicos} .2021 .47990$

alternadamente meninos e meninas. E, como é uma escola com um alto índice de inclusão, havia um aluno com laudo de autista e outro com paralisia cerebral que também participaram da atividade, pois o jogo assim permitia.

Em nossa primeira mediação buscamos apresentar o jogo como atividade livre e o resultado foram reações de colaboração enfática a cada um que sentava em frente ao jogo, como uma torcida para que o outro triunfasse. Tal participação trouxe à tona a necessidade de prestar a atenção não só no computador - nas teclas, no mouse ou no gráfico da animação do jogo - mas nas regras que faziam vencer o jogo: completar a dezena (positiva) através da soma de números positivos e negativos. E ainda, que padrões ocorriam no jogo e que o Scratch deveria observar para tocar nos números positivos e negativos desejados.

Em uma interferência para ajudar o colega que estava jogando, os alunos deram a seguinte dica:

Alunos da turma: Tá negativo, é preciso pegar os positivos pra passar do zero!

Tal dica se refere à seguinte tela (FIGURA 4):

Figura 4 - Telas: à esquerda com a soma negativa e à direita depois de vencerem o jogo Scratch no Deserto.

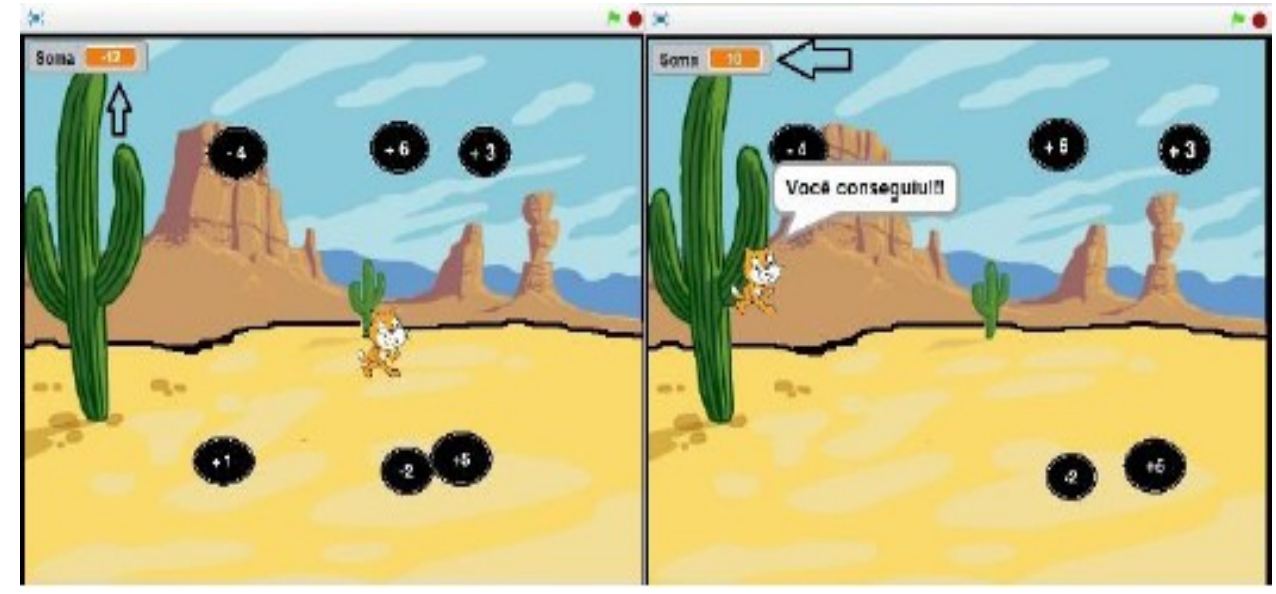

Fonte: Autores (2019)

Durante esta primeira mediação colaboraram, torciam uns pelos outros, buscavam estratégias e padrões existentes na soma de positivos e negativos e podemos indicar que focaram, gradativamente nesta ordem, no notebook, nos padrões e regras do jogo e na 
DOI: $10.12957 /$ e-mosaicos.2021.47990

matemática produzida resultante das inferências mútuas. $\mathrm{O}$ que permitiu que cada aluno na sequência para jogar conseguisse vencer o jogo cada vez mais rápido e descrevendo juntos o que devam fazer e o porquê. A alegria pelo sucesso do outro e da própria turma em descobrir como venciam o jogo ficou notório. Também percebemos que

O interesse que a criança tem pelos jogos faz com que prazerosamente ele aplique sua inteligência e seu raciocínio no sentido de obter o êxito. Assim sendo, ao jogar, o sujeito realiza uma tarefa, produz resultados, aprende a pensar num contexto em que enfrentar os desafios e tentar resolvê-los são imposições que ele faz a si próprio. (BRENELLI, 2012, p.173)

Para fomentar então a mudança de mediação, o primeiro autor sugeriu que iria jogar e assim gostaria de ser ajudado.

Aluno 4:Mas você é adulto,não precisa de ajuda.

Aluna 5: E você conhece o jogo, não precisa..

Professor-pesquisador 1: Mas quem sabe vocês me dão dicas melhores do que eu sei?! Ou ainda me ensinam uma maneira melhor pra ganhar.

A cada pergunta que fazíamos buscando a ajuda da turma, naturalmente, ela dava sua contribuição mostrando solidariedade para que o primeiro autor pudesse aprender novas estratégias para vencer 0 jogo. Em determinado momento sugerimos uma competição entre lados da sala (esquerda contra a direita) que possuíam uma mistura de gêneros ou meninos contra meninas. Por uma ampla margem, decidiram que haveria uma competição entre gêneros. Contudo, queremos ressaltar que a votação dentre os 19 presentes - 10 meninos e 09 meninas - contou com 14 votos a 5 , sendo todos os votos contrários à competição de meninas e algumas que foram a favor nitidamente por resiliência, como se não fizesse diferença a competição ser entre ser entre os lados ou entre gêneros. Foram então negociadas novas regras onde o time que somasse o menor tempo de vencer o jogo seria o vencedor.

A mudança foi imediata. Passaram a cooperar dentro de seus grupos, porém com uma cobrança e reclamações a cada tempo que consideravam ruim, principalmente dentro do grupo dos meninos. A cada marcação de tempo foram percebidos alegria e alívio quando terminavam o jogo, mas tristeza quando não corresponderam às expectativas dos outros colegas, medo de participar e nervosismo ao jogarem e até mesmo raiva a cada marcação de tempo. 
DOI: $10.12957 / \mathrm{e}-\mathrm{mosaicos} .2021 .47990$

Em nossa marcação de tempo os meninos, gradativamente, sentiam que estavam perdendo e alguns chegaram a reações um tanto quanto violentas como gritar, um menino chegou a socar a mesa e chorar. Outros chegaram a falar "Poxa, por que fui ajudar as meninas?", referindo-se a ajuda que deu a uma colega na mediação anterior. Por fim, devido a mais um ajuste de regras pelo desequilíbrio entre gêneros, houve um empate que causou uma decepção entre os meninos.

Professor-pesquisador 2: Mas empatar não é bom, todos ganham?!

Aluno 1:Empate não é ganhar..

Aluna 3: Eu achei legal...

Reparamos que, de maneira geral as meninas entenderam o que a segunda autora tentou explicar, contudo os meninos mantiveram-se em sua maioria intransigentes e não aceitaram empatar com as meninas, pois externaram que precisavam ganhar delas. Mas de maneira geral observamos que nesta mediação, apesar de usarem a matemática para vencerem o jogo, esqueceram de estratégias matemáticas novas, focaram em ganhar e cobrar o acerto a qualquer custo e não perdoavam a falta de habilidade de um colega com críticas e falas de decepção. As reações foram bastante preocupantes, socialmente falando.

Após a atividade o primeiro e terceiro autor deixaram a sala de aula e a segunda e quarta autoras verificaram que, mesmo ainda tentando através de reflexões, fazer com que 0 entendimento sobre o empate não fosse ruim, um menino permaneceu triste, choroso e pedindo revanche até a hora da saída. Um dos colegas então faz uma confidência, dizendo que tal menino é cheio de troféus em casa, que não aceita perder.

\section{CONSIDERAÇõES SOBRE AS MEDIAÇÕES: JOGAR X COMPETIR}

Lembramos que estávamos visando, mais do que desenvolvimento dos estudantes frente a um possível novo desafio conceitual matemático, observar como eles reagiriam perante cada tipo de mediação a que estariam expostos e que aspectos emergem quando um jogo é ou não é transformado em uma competição num ambiente escolar. Dessa forma, ficou claro que com a primeira mediação onde apenas deixamos jogar, livres e sem interferência sobre a maneira de agirem, suas reações promoveram interação e aprendizagem de uma maneira que não causou desprazer em momento algum.

Na segunda mediação intencional, transformando o jogo em uma competição, nos transpareceu que a vontade de ganhar do outro era maior, como se o jogo não importasse e sim a vitória, como se tivessem jogado sem outro objetivo que não a vitória. 
DOI: $10.12957 / \mathrm{e}-\mathrm{mosaicos} .2021 .47990$

Diferente dos primeiros momentos, onde todos se ajudaram, solidarizaram-se com os outros colegas e a intenção era levar o outro ao objetivo para que todos se sentissem agraciados, na segunda mediação, ainda que usassem a matemática para chegarem aos seus objetivos, a possível derrota era motivo de tristeza e a vitória o motivo de se estar jogando.

Assim, traçamos uma linha de observação entre as reações quando um jogo é só uma atividade lúdica e que naturalmente traz prazer e sensação de pertencimento ao aprenderem juntos e quando transformamos, através da mediação, um jogo numa competição. Percebemos que a mudança entre colaboração para cooperação ocorreu, que a violência esteve presente de diversas formas, desde as psicológicas até físicas. Assim, voltamos a nos perguntar: no nosso contexto escolar e acadêmico, que conotação damos à palavra competição? Será que todo jogo pressupõe uma competição? Aliás, quais deveriam ser os nossos pressupostos? Os biológicos, os psicológicos, empresariais e mercadológicos ou predominantemente os pedagógicos? Mais ainda, o que são na prática esses pressupostos pedagógicos?

Essa experiência aqui relatada traz pistas sobre como os métodos de ensino, em particular utilizando o recurso jogos, tem implicações sociais na aquisição de conhecimentos, na produção de sentidos em que tais conhecimentos estarão atrelados e que, por isso, merecem uma delicada atenção na prática e desenvolvimento docente. Encerramos numa necessidade de formar verdadeiras pontes entre teorias e práticas no que se refere ao desenvolvimento social e humano em nível escolar e, por que não acadêmico, sobre o uso dos recursos, mas principalmente sobre a mediação que realizamos para a aquisição, construção ou até mesmo fixação de conceitos matemáticos.

Entendemos que não se trata só de matemática, só de pedagogia ou só de recursos e tecnologia, mas que elas estão entrelaçadas pelo tipo de mediação e que tal mediação trará consequências sociais através dessas pontes. Assim, consideramos ser importante jogar sim, enquanto atividade lúdica que corrobora com o ensinar e aprender, mas o competir precisa ser melhor compreendido para que possa ser favorecido conscientemente, ou não - como preferimos -, dentro dos contextos escolares.

\section{REFERÊNCIAS}

ADLER, J. Journal of Mathematics Teacher Education. Kluwer Academic Publishers. Printed in the Netherlands (3) 205-224, 2000.

ADLER, J. Resources as a verb: Recontextualising resources in and for school mathematics practice. In A. Olivier \& K. Newstead (Eds.), Proceedings of the 22nd Conference of the 
DOI: $10.12957 / \mathrm{e}-\mathrm{mosaicos} .2021 .47990$

International Group of the Psychology of Mathematics Education, Vol. 1 (1-18).

Stellenbosch, South Africa: University of Stellenbosch, 1998a.

BERNSTEIN, B. Class, codes and control: the structuring of pedagogic discourse. Londres: Routledge; Taylor \& Francis Group, 2003.

BEZERRA, S. M. C. B.; BANDEIRA, S. M. C. Metodologias alternativas no ensino da matemática: jogos e oficinas pedagógicas. Revista Ramal de Ideias. Rio Branco, v. 1, n. 1, p. 1-16, 2008. Disponível em:

<http://www.ufac.br/portal/unidades-administrativas/orgaos-complementares/edufac/ revistas-eletronicas/revista-ramal-de-ideias/edicoes/edicao-1/caminhos-dos-numeros/ metodologias-alternativas-no-ensino-da-matematica>. Acesso em: 19 abril de 2019.

BOALER, J. Mentalidades matemáticas: estimulando o potencial dos estudantes por meio da matemática criativa, das mensagens inspiradoras e do ensino inovador. 1ed. Tradução: Daniel Bueno. Revisão: Fernando Amaral Carnaúba; Isabele Veronese; Patrícia Cândido. Porto Alegre: Penso, 2018.

BRASIL. Base Nacional Curricular Comum. Brasília: MEC, 2017. BRASIL. Instituto Nacional de Estudos e Pesquisas Educacionais Anísio Teixeira.

BROTTO, F. O. Jogos cooperativos: o jogo e o esporte como um exercício de convivência. 1999. 209 f. Dissertação (Mestrado em Educação Física) - Faculdade de Educação Física, Universidade Estadual de Campinas, Campinas, 1999.

ELIAS, N.; DUNNING, E. A busca da excitação. Lisboa: Difelm, 1992.

FREIRE, P. Pedagogia da Autonomia: saberes necessários a pratica educativa. São Paulo: paz e terra, 1996 (coleção leitura). 21 ed, 2002.

GRANDO, R.C. O Conhecimento Matemático e o Uso de Jogos na Sala de Aula. 2000. $239 f$. Tese (Doutorado), Universidade Estadual de Campinas, Campinas, 2000.

HUIZINGA, J. Homo Ludens: o jogo como elemento cultural. São Paulo: Perspectiva, 1990. LARA, I. C. M. Jogando com a Matemática de 5a a 8a série. São Paulo: Rêspel, 2004.

MIORIM, M. A., FIORENTINI, D. Uma reflexão sobre o uso de materiais concretos e jogos no Ensino da Matemática. Boletim da SBEM-SP, São Paulo, v. 4, n. 7, p. 5-10, 1997. 
DOI: $10.12957 / \mathrm{e}-\mathrm{mosaicos} .2021 .47990$

RONDINELLI, P. Jogos: entre a cooperação e a competição. Brasil Escola. Disponível em: https://brasilescola.uol.com.br/educacao-fisica/jogos-entre-cooperacao-competicao.htm. Acesso em 16 de junho de 2019.

SILVA, A. M. O brincar no contexto escolar. significados das brincadeiras realizadas em aulas de educação física e no recreio. Dissertação (mestrado em Educação Física). Faculdade de Educação Física, Universidade Estadual de Campinas, 2010.

SMOLE, K. S.; DINIZ, M. I.; MILANI, E. Cadernos do Mathema - Jogos de Matemática de $6^{\circ}$ a $9^{\circ}$ ano. Porto Alegre: Artmed, 2007.

TOWNSEND, C. R.; BEGON, M.; HARPER, J. L. Fundamentos em Ecologia. Porto Alegre: Artmed 3ed. pp. 211-212, 2010.

Recebido em 21 de janeiro de 2020

Aceito em 10 de março de 2021

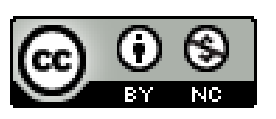

A e-Mosaicos Revista Multidisciplinar de Ensino, Pesquisa, Extensão e Cultura do Instituto de Aplicação Fernando Rodrigues da Silveira (CAp-UERJ) está disponibilizada sob uma Licença Creative Commons - Atribuição - NãoComercial 4.0 Internacional.

Os direitos autorais de todos os trabalhos publicados na revista pertencem ao(s) seu(s) autor(es) e coautor(es), com o direito de primeira publicação cedido à e-Mosaicos.

Os artigos publicados são de acesso público, de uso gratuito, com atribuição de autoria obrigatória, para aplicações de finalidade educacional e não-comercial, de acordo com o modelo de licenciamento Creative Commons adotado pela revista. 